\title{
Diagnostic Accuracy of Dual-Layer Spectral CT Using Electron Density Images to Detect Post-Traumatic Prevertebral Hematoma of the Cervical Spine
}

\author{
Diagnostische Wertigkeit der Dual-Layer-Spektral-CT zur Detektion \\ von posttraumatischen prävertebralen Hämatomen der \\ Halswirbelsäule unter Verwendung von Elektronendichtebildern
}

Authors

Sam Sedaghat ${ }^{10}$, Patrick Langguth ${ }^{1}$, Naomi Larsen ${ }^{10}$, Graeme Campbell ${ }^{2}$, Marcus Both ${ }^{1}$, Olav Jansen ${ }^{1}$

Affiliations

1 Department for Radiology and Neuroradiology, University Hospital Schleswig-Holstein - Campus Kiel, Germany

2 Clinical Science, Philips, Hamburg, Germany

Key words

dual-layer spectral CT, diagnostic accuracy, prevertebral hematoma, electron density

received 17.02.2021

accepted 05.06.2021

published online 05.08 .2021

\section{Bibliography}

Fortschr Röntgenstr 2021; 193: 1445-1450

DOI 10.1055/a-1529-7010

ISSN $1438-9029$

(c) 2021. Thieme. All rights reserved.

Georg Thieme Verlag KG, Rüdigerstraße 14,

70469 Stuttgart, Germany

Correspondence

Dr. Sam Sedaghat

Department for Radiology and Neuroradiology, University

Hospital Schleswig-Holstein, Campus Kiel,

Arnold-Heller-Str. 3, 24105 Kiel, Germany

Tel.: $+49 / 163 / 9639740$

samsedaghat1@gmail.com

\section{ZUSAMMENFASSUNG}

Zielsetzung Untersuchung der diagnostischen Wertigkeit der Dual-Layer-Spektraldetektor-Computertomografie (SDCT) zur Erkennung von posttraumatischen prävertebralen Hämatomen der Halswirbelsäule unter Verwendung von Elektronendichtebildern.

Methoden 38 Patienten mit posttraumatischer Bildgebung der Halswirbelsäule wurden in diese Studie eingeschlossen und erhielten sowohl SDCT- als auch MRT-Untersuchungen. Die MRT wurde als Referenz festgelegt. Kombinierte konventionelle und Elektronendichtebilder (C+ED) wurden mit konventionellen Bildern (CCT) verglichen.
Ergebnisse Insgesamt wurden 18 prävertebrale Hämatome identifiziert. Reader 1 identifizierte 14 von 18 und Reader 2 15 von 18 prävertebrale Hämatome unter Verwendung von C + ED-Bildern. Reader 1 und 2 entdeckten 6 bzw. 9 von 18 Hämatomen mittels CCT. Bei CCT-Bildern zeigte sich eine Sensitivität von 33-50\% und eine Spezifität von 75-80\%, während für C + ED-Bilder eine Sensitivität von 77-83\% und eine Spezifität von 85-90\% ermittelt wurde. Die Genauigkeit wurde unter Verwendung von C+ ED-Bildern von 55-66\% auf $84 \%$ erhöht. Die Mindestdicke zum Nachweis von Hämatomen auf C + ED-Bildern betrug $3 \mathrm{~mm}$. Das Ausmaß der prävertebralen Hämatome wurde weder bei CCT- noch bei C + ED-Bildern im Vergleich zur MRT-Referenz signifikant unter- oder überschätzt. Dagegen gab es einen signifikanten Unterschied zwischen den beiden Readern in Bezug auf die Messung der Hämatomgrößen in CCT-Bildern $(p=0,04)$. Die Reader zeigten eine exzellente Interrater-Übereinstimmung (kappa $=0,82)$ für C + ED-Bilder und eine moderate Interrater-Übereinstimmung (kappa $=0,44)$ für CCT-Bilder.

Schlussfolgerung Durch die Verwendung von kombinierten konventionellen und Elektronendichtebildern lässt sich bei der SDCT die diagnostische Genauigkeit zur Erkennung von posttraumatischen prävertebralen Hämatomen im Vergleich zu konventionellen Bildern steigern.

\section{Kernaussagen:}

- SDCT hat ein hohes Potenzial zur Erkennung von posttraumatischen prävertebralen Hämatomen der Halswirbelsäule unter Verwendung von kombinierten konventionellen und Elektronendichtebildern.

- Prävertebrale Hämatome mit einer Dicke von weniger als $3 \mathrm{~mm}$ können durch die SDCT nicht sicher identifiziert werden.

- Konventionelle SDCT-Bilder sind für die Diagnose eines prävertebralen Hämatoms ungeeignet.

\section{ABSTRACT}

Purpose To investigate the diagnostic value of dual-layer spectral detector computed tomography (SDCT) in detecting posttraumatic prevertebral hematoma of the cervical spine by including electron density images. 
Methods 38 patients with post-traumatic imaging of the cervical spine were included in this study and received both SDCT and MRI examinations. MRI was set as the reference and combined conventional/electron density $(C+E D)$ images were compared to conventional CT (CCT) images alone.

Results A total of 18 prevertebral hematomas were identified. Reader 1 identified 14 of 18 and reader 215 of 18 prevertebral hematomas by using $\mathrm{C}+\mathrm{ED}$ reconstructions. Readers 1 and 2 detected 6 and 9 of 18 hematomas on CCT, respectively. CCT showed a sensitivity of $33-50 \%$ and a specificity of $75-80 \%$, while for C + ED reconstructed images the sensitivity was $77-83 \%$ and the specificity was $85-90 \%$. Accuracy increased from $55-66 \%$ to $84 \%$ by using C + ED images. The minimum thickness for detecting hematoma on C+ED images was $3 \mathrm{~mm}$. The sizes of prevertebral hematoma on CCT/ $\mathrm{C}+\mathrm{ED}$ were not significantly under- or overestimated compared to the MRI reference. There was a significant difference between the two readers for measuring hematoma sizes on CCT $(p=0.04)$. Readers showed an excellent inter-rater reliability (kappa $=0.82$ ) for $C+E D$ images and a moderative inter-rater reliability $(\mathrm{kappa}=0.44)$ for $\mathrm{CCT}$.
Conclusion With SDCT, the diagnostic accuracy for detecting post-traumatic prevertebral hematoma is improved by using combined conventional and electron density reconstructions compared to conventional images alone.

\section{Key Points:}

- SDCT has a high potential for detecting post-traumatic prevertebral hematomas of the cervical spine by using combined conventional and electron density images.

- Prevertebral hematomas with a thickness of less than $3 \mathrm{~mm}$ cannot be reliably identified by SDCT.

- There is no discernible value of conventional SDCT images for diagnosing prevertebral hematoma.

\section{Citation Format}

- Sedaghat S, Langguth P, Larsen N et al. Diagnostic Accuracy of Dual-Layer Spectral CT Using Electron Density Images to Detect Post-Traumatic Prevertebral Hematoma of the Cervical Spine. Fortschr Röntgenstr 2021; 193: 1445-1450

\section{Introduction}

In the emergency setting, fractures of the spine are frequently suspected and often require immediate operative care. Older patients with degenerative changes of the spine are particularly at risk of fracture [1-3]. The imaging modalities typically used initially for these patients are conventional radiographs or computed tomography (CT) [4]. Since the mid-1990 s, CT has become increasingly more important in this setting and is currently the imaging modality of choice for evaluating spinal fractures [5]. However, as soon as further information regarding the status of adjacent soft tissue becomes necessary, MRI is required, which is the modality of choice for evaluating ligaments and soft tissues [4-6]. Moreover, the increasing resolution of $C T$ raises the question as to what extent structures can be visualized with the latest $\mathrm{CT}$ technology, which might obviate the need for additional MRI examinations. These concomitant injuries include prevertebral hematomas (also called retropharyngeal hematomas) [7]. Prevertebral hematomas occur only rarely and are treated surgically in clinically unstable patients or when hematomas are not reabsorbed [8-11]. A relatively recent and unique innovation is dual-layer spectral computed tomography (SDCT), which uses one X-ray tube and two detector layers, whereby the detector layers absorb high- and low-energy spectra from the polychromatic X-ray beam. Here, spectral information can be reconstructed and material decomposed in order to provide spectral results, such as iodine concentration or electron density, for all patients on demand [12-14]. The attenuation of X-rays at a particular energy level through a material is dependent on both the effective atomic number and the density of that material. The heightened hemoglobin content at the site of a hematoma increases the material density at this location with a minimal effect on the average atomic number, suggesting that electron density images provided from SDCT could improve hematoma detection. For this reason, we investigated the diagnostic value of SDCT in detecting post-traumatic prevertebral hematoma of the cervical spine. We hypothesized that electron density images can improve the diagnostic accuracy for detecting hematoma compared to conventional CT.

\section{Methods}

\section{Patients}

Between June 2019 and May 2020, we identified 48 patients in whom both post-traumatic MRI and SDCT of the cervical spine were performed. In 4 patients, SDCT data reconstructions were faulty, in 4 patients artifacts were present owing to dorsal spondylodesis, in one patient the dataset showed an error, and in another patient the time between MRI and SDCT was over 24 hours. Ultimately, 38 patients who had received both MRI and SDCT examinations within 24 hours after admission to the emergency room were included in this study.

\section{CT imaging}

The patients were examined using a dual-layer detector CT unit (Spectral IQON ${ }^{\circledR}$, Philips Healthcare, the Netherlands). CT images were acquired using a tube voltage of $120 \mathrm{kVp}$, an automated attenuation-based dose modulation (DoseRight, Philips Healthcare), a rotation time of $0.27 \mathrm{~s}$, a collimation of $64 \times 0.625$, and a slice thickness of $1 \mathrm{~mm}$. Additionally, conventional images and spectral images were reconstructed using iDose level 2 (Philips Healthcare, the Netherlands) and Spectral level 2 (Philips Health- 
care, the Netherlands), respectively. For comparison of SDCT and MRI, sagittal images were reconstructed and evaluated with a slice thickness of $3 \mathrm{~mm}$. From the same dataset, both conventional (CCT) images and overlaid conventional/electron density $(C+E D)$ images were analyzed.

\section{MR imaging}

Here, examinations using 1.5 T MRI (Achieva, Philips Healthcare and Aera, Siemens Healthineers) were performed. The following imaging sequences were analyzed: T1w TSE sagittal (TE: 7-12 ms TR: 400-654 ms, FOV: 51-102 cm), T2w sagittal (TE: 80-120 TR: 1857-4322 FOV 51-113), and short tau inversion recovery sequence (STIR) in sagittal plane (TE: 70-80 TR: 2500-7430 FOV $53-113 \mathrm{~cm})$. The slice thickness was $3 \mathrm{~mm}$.

\section{Imaging analysis}

MRI was set as the reference and prevertebral hematomas were measured by a blinded reader. The reader identified the cervical level of the prevertebral hematomas and measured the thickness (depth) and height of these findings on sagittal MRI images (STIR). Afterwards, two other readers with 5 and 7 years of experience in trauma diagnostics first tried to determine the optimal reconstruction of electron density SDCT images on IntelliSpace Portal (Philips Healthcare) for detecting prevertebral hematoma. The favored combination resulted in a sagittal overlay of conventional and electron density images. Thereafter, the two readers independently reviewed both CCT and C + ED images on the IntelliSpace Portal. According to the MRI reference, the readers identified the thickness (depth) and height of the hematomas in conventional and overlaid sagittal SDCT images. In each case, the slice with the greatest extent of hematoma was taken for measurement. In addition, hematological parameters (hemoglobin and hematocrit) of the patients were reviewed to investigate a possible correlation with undetectable hematomas.

\section{Statistical analysis}

Data are given as median values with range (minimum to maximum) or mean and standard deviation (SD). Parametric and nonparametric tests to compare group values ( $\mathrm{t}$ - and $\mathrm{X}$ 2-test, MannWhitney U-test, ANOVA) were performed as indicated. Sensitivity, specificity, accuracy, and positive and negative predictive values were assessed in contingency tables. The inter-reader agreement for Likert scales was performed with weighted Cohen's $\mathrm{K}$ statistics. Statistical significance for all tests was set at a level of $p<0.05$. Statistical analysis was done using the IBM-SPSS version 26.0 software package (IBM, Armonk, NY, USA).

\section{Ethics approval}

The study was approved by the responsible Institutional Review Board (IRB).

\section{Results}

The mean age of the patients was 63 years (min.: 23, max.: 93, SD: 22,9$)$. Of the patients, $55 \%$ were female $(n=21)$ and $45 \%$
- Table 1 Summary of false-positive/-negative and true-positive/negative resultsfor conventional images (CCT) and combined conventional/electron density images $(C+E D)$.

- Tab.1 Zusammenfassung der falsch positiven/negativen und richtig positiven/negativen Ergebnisse für konventionelle Bilder (CCT) und kombinierte konventionelle Elektronendichtebilder (C+ED).

\begin{tabular}{|c|c|c|c|c|}
\hline \multirow{2}{*}{$\begin{array}{l}\text { detection of } \\
\text { prevertebral } \\
\text { hematoma }\end{array}$} & \multicolumn{2}{|c|}{ reader 1} & \multicolumn{2}{|c|}{ reader 2} \\
\hline & CCT & $C+E D$ & CCT & $C+E D$ \\
\hline true positive & 6 & 14 & 9 & 15 \\
\hline false positive & 5 & 2 & 4 & 3 \\
\hline false negative & 12 & 4 & 9 & 3 \\
\hline true negative & 15 & 18 & 16 & 17 \\
\hline
\end{tabular}

male $(n=17)$. 18 prevertebral hematomas of the cervical spine detected on MR imaging were included ( $\triangleright$ Fig. 1, 2). Reader 1 identified 14 of 18 (78\%) and reader 2 identified 15 of 18 (83\%) prevertebral hematomas correctly and certainly by using $\mathrm{C}+\mathrm{ED}$ reconstructions. However, 6 of 18 (33\%) and 9 of 18 (50\%) hematomas were seen on conventional CT by reader 1 and 2 , respectively ( $\triangleright$ Table 1 ). Conventional CT images showed a sensitivity of $33-50 \%$ and a specificity of $75-80 \%$, while C + ED reconstructed images had a sensitivity of $77-83 \%$ and a specificity of $85-$ $90 \%$. Accuracy increased from $55-66 \%$ to $84 \%$ by using overlaid $\mathrm{C}+$ ED images ( $\triangleright$ Table 2 ).

Both readers declared that the minimum thickness of hematoma for detection on C $+E D$ images was $3 \mathrm{~mm}$. Accordingly, three hematomas not detected by readers 1 and 2 on C + ED images had a maximum thickness of $3 \mathrm{~mm}$. One hematoma not detected by reader 1 showed a thickness of $4 \mathrm{~mm}$. Both reviewers also declared that the reliability for detecting hematomas grew with the thickness of the hematoma. The height of prevertebral hematoma and hematological parameters had no significant impact on hematoma detection. Therefore, the thickness remained the only objective limiting factor for undetected hematomas. The sizes of prevertebral hematoma on conventional and spectral CT were not significantly under- or overestimated by either reader compared to the MRI reference, with a mean deviation of $1 \mathrm{~cm}^{2}$ on spectral CT (min.: 0.2, max.: 2.8, SD: 0.8 ) and $1.3 \mathrm{~cm}^{2}$ on conventional CT (min.: 0, max.: 3.7, SD: 1). There was a significant difference between the two readers in measuring hematoma sizes on conventional images $(p=0.04)$. None of the undetected hematomas by $C+E D$ reconstructions needed surgical treatment. Inter-reader agreement was moderate for conventional CT images $(\mathrm{K}=0.44$; asymptotic SD: $0.2 ; \mathrm{p}<0.046)$ and excellent for overlaid spectral CT images ( $\mathrm{K}=0.82$; asymptotic SD: $0.17 ; \mathrm{p}<0.001)$. 


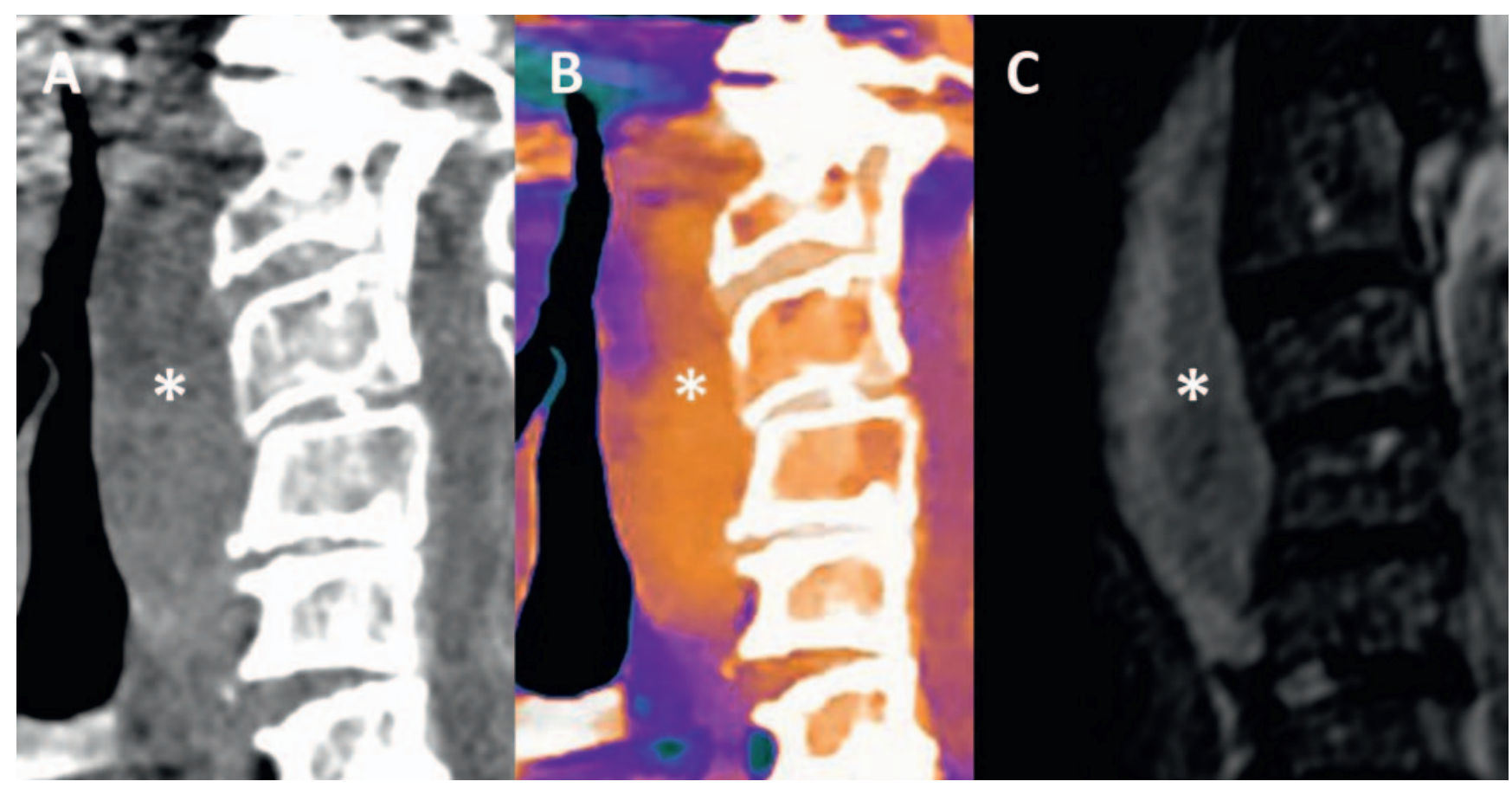

- Fig. 1 Prevertebral hematoma (*) is shown on conventional A and reconstructed conventional/electron density B SDCT images (sagittal). C shows the 1.5 T MRI reference (STIR sagittal).

- Abb. 1 Prävertebrales Hämatom ( ${ }^{*}$ ) auf konventionellen A und kombinierten konventionellen Elektrondichtebildern B (sagittal). C zeigt die 1,5T-MRT-Referenz (STIR sagittal).

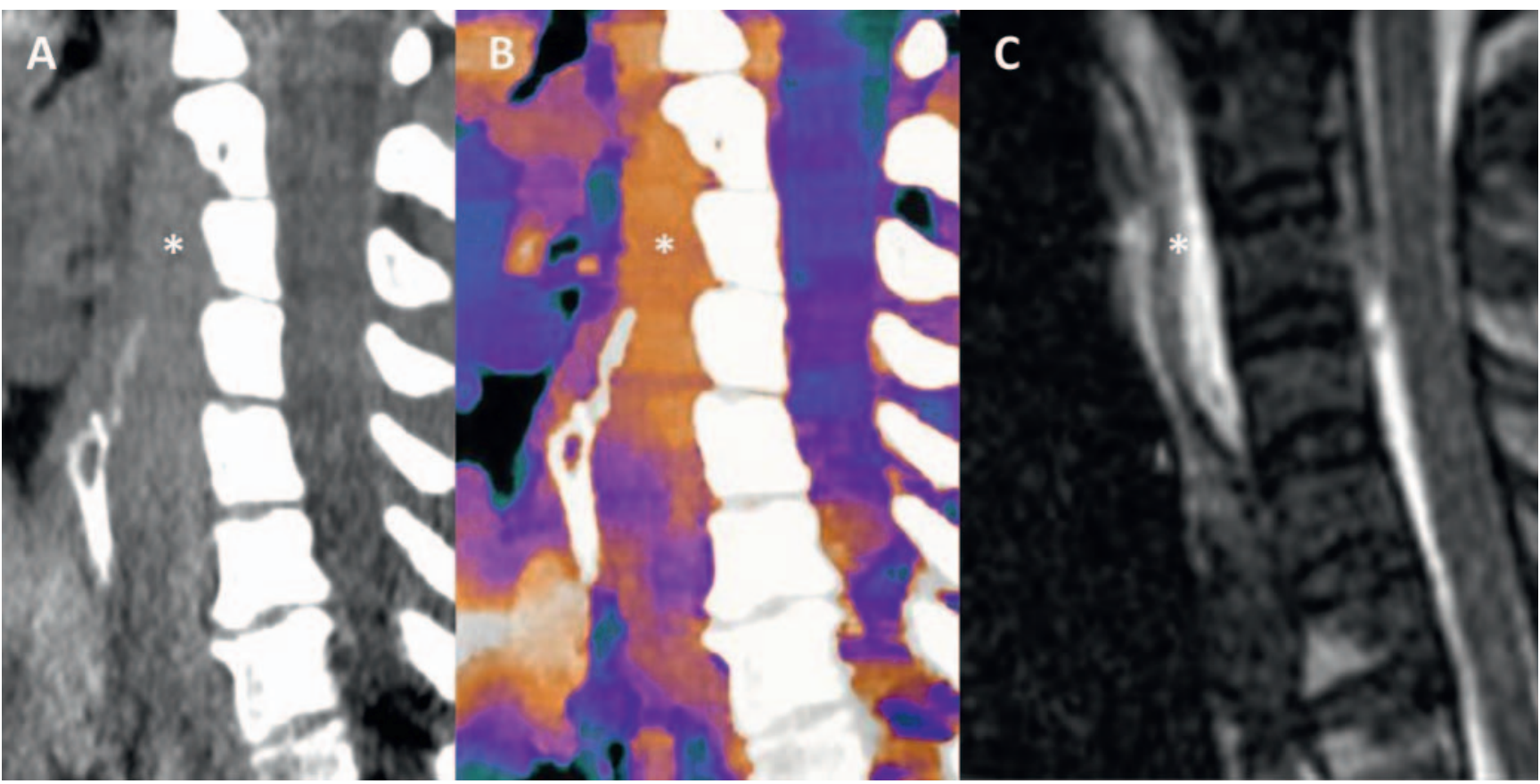

- Fig. 2 : Prevertebral hematoma $\left({ }^{*}\right)$ on conventional SDCT A, reconstructed conventional/electron density SDCT B and 1.5 T MRI (STIR) images C, all shown in sagittal view.

- Abb. 2 Prävertebrales Hämatom ( ${ }^{*}$ ) auf konventionellen SDCT- A, kombinierten konventionellen Elektronendichte-SDCT- B und 1,5T-MRI (STIR) -Bildern C, allesamt in sagittaler Rekonstruktion. 
- Table 2 Diagnostic accuracy of SDCT for detecting post-traumatic prevertebral hematomas of the cervical spine by using conventional images (CCT) and combined conventional/electron density images (C+ED).

- Tab.2 Diagnostische Wertigkeit der SDCT zur Detektion von posttraumatischen prävertebralen Hämatomen der Halswirbelsäule unter Verwendung von konventionellen Bildern (CCT) und kombinierten konventionellen Elektronendichtebildern (C+ED).

\begin{tabular}{|c|c|c|c|c|}
\hline \multirow[t]{2}{*}{ detection of prevertebral hematoma } & \multicolumn{2}{|l|}{ reader 1} & \multicolumn{2}{|l|}{ reader 2} \\
\hline & CCT & $C+E D$ & CCT & $C+E D$ \\
\hline sensitivity & $\begin{array}{l}33 \% \\
\text { (95\% Cl: 13-59\%) }\end{array}$ & $\begin{array}{l}77 \% \\
(95 \% \text { Cl: 52-94\%) }\end{array}$ & $\begin{array}{l}50 \% \\
(95 \% \text { Cl: } 26-74 \%)\end{array}$ & $\begin{array}{l}83 \% \\
\text { (95\% Cl: 59-96\%) }\end{array}$ \\
\hline specificity & $\begin{array}{l}75 \% \\
\text { (95\% Cl: 51-91\%) }\end{array}$ & $\begin{array}{l}90 \% \\
(95 \% \text { Cl: 68-99\%) }\end{array}$ & $\begin{array}{l}80 \% \\
(95 \% \text { Cl: } 56-94 \%)\end{array}$ & $\begin{array}{l}85 \% \\
\text { (95\% Cl: 62-97\%) }\end{array}$ \\
\hline positive predictive value & $\begin{array}{l}55 \% \\
\text { (95\% Cl: 31-77\%) }\end{array}$ & $\begin{array}{l}88 \% \\
(95 \% \text { Cl: 65-96\%) }\end{array}$ & $\begin{array}{l}69 \% \\
(95 \% \text { Cl: 46-86\%) }\end{array}$ & $\begin{array}{l}83 \% \\
\text { (95\% Cl: 63-94\%) }\end{array}$ \\
\hline negative predictive value & $\begin{array}{l}56 \% \\
(95 \% \text { Cl: } 45-65 \%)\end{array}$ & $\begin{array}{l}82 \% \\
\text { (95\% Cl: 65-92\%) }\end{array}$ & $\begin{array}{l}64 \% \\
\text { (95\% Cl: 52-75\%) }\end{array}$ & $\begin{array}{l}85 \% \\
\text { (95\% Cl: 67-94\%) }\end{array}$ \\
\hline accuracy & $\begin{array}{l}55 \% \\
\text { (95\% Cl: 38-71\%) }\end{array}$ & $\begin{array}{l}84 \% \\
\text { (95\% Cl: 69-94\%) }\end{array}$ & $\begin{array}{l}66 \% \\
\text { (95\% Cl: 49-80\%) }\end{array}$ & $\begin{array}{l}84 \% \\
\text { (95\% Cl: 69-94\%) }\end{array}$ \\
\hline
\end{tabular}

\section{Discussion}

In this study we investigated the diagnostic accuracy of SDCT in detecting post-traumatic prevertebral hematoma of the cervical spine. To this end, we compared conventional (CCT) images with overlaid conventional/electron density ( $C+E D)$ images.

Prevertebral hematoma is a rare, but critical condition with the danger of progressive blood loss, arytenoid cartilage compression, and airway obstruction when the hematoma expands [8, $11,15-17]$. It develops in the front of the cervical spine and is located between the pharynx and the spine [11]. Prevertebral hematoma is usually detected at higher cervical levels (C2 and C3) $[7,18]$. In the last few years, studies of prevertebral hematomas on CT have moved more and more into the background, as MRI is regarded as the imaging modality of choice for the detection of ligamentous structures, soft-tissue changes, and even small hematomas [19, 20]. Nevertheless, MRI is time-consuming and not feasible for all patients, especially for patients with metal devices [21, 22]. In trauma and emergency settings, in particular, quick diagnosis is needed to initiate further therapy. As CT is increasingly replacing $X$-ray [18], the question arises as to whether acute injuries other than fractures can be identified by CT using optimized images. A relatively new scanner, a dual-layer spectral CT (SDCT), was used in this study. SDCT differs from other dualenergy CT (DECT) methods (for example, dual-source) in that it has one X-ray tube and two detector layers $[12,13]$. SDCT absorbs low-energy photons in the inner layer and higher-energy photons in the outer layer of the detector [3, 23]. The simultaneous acquisition of low- and high-energy spectra helps to reduce noise, thereby improving the spectral separation [23, 24], and multiple spectral images can be created (e. g., iodine density, virtual noncontrast-enhanced, or electron density) [14]. Previous studies on SDCT in emergency and trauma settings concentrated on the use of calcium-suppression tools for detecting bone marrow edema $[3,13,24,25]$, but no study has examined post-traumatic prever- tebral hematoma on SDCT yet. Furthermore, no previous study has used electron density reconstructions to detect prevertebral hematoma. The concept of using electron density images is already being applied in radiotherapy planning to estimate the dose to be delivered [26, 27].

The standard MRI protocol used in the reference MRIs was noncontrast-enhanced, sagittal T1w, T2w, and STIR images, according to previous studies [19]. For comparison, SDCT images were reconstructed using multiplanar reformation (MPR). Before starting this study, we examined different types of reconstructions and imaging combinations, ultimately determining that combined conventional and electron density images were most accurate. Previous studies suggest that conventional CT has limited value regarding prevertebral hematoma and increased prevertebral soft-tissue thickness is considered as an indirect sign of prevertebral hematoma $[5,18,28]$. In our study conventional CT did not deliver reliable diagnostic accuracy either, with a sensitivity of $33-50 \%$ and a specificity of $75-80 \%$. However, combined $\mathrm{C}+$ ED images improved the diagnostic accuracy and showed a sensitivity of $77-83 \%$ and a specificity of $85-90 \%$. The diagnostic accuracy increased from $55-66 \%$ to $84 \%$ by using overlaid C + ED images. These findings suggest that SDCT with combined $C+E D$ images may be used in the emergency setting to pre-evaluate patients with prevertebral hematomas and could eliminate the need for further imaging in some patients or provide an alternative for patients in whom MRI is contraindicated. Furthermore, patients with critical airway obstruction and other complications of prevertebral hematoma could be treated more quickly. However, caution is needed when interpreting these findings. While in large hematomas SDCT with $\mathrm{C}+\mathrm{ED}$ reconstructions can be feasible in a routine clinical setting, small hematomas with a thickness of $3 \mathrm{~mm}$ or less remain undetectable by SDCT. In our study, the thickness of the hematoma was the only objective limitation for undetected hematomas on C + ED reconstructions. Also, hematological parameters, for example, do not play a role in this ques- 
tion. None of the undetected hematomas had to be treated surgically. Conversely, our results show that the $C+D$ images can usually detect large hematomas that require treatment. Furthermore, $C+E D$ reconstructions are not as precise as MRI in determining hematoma size, as hematoma sizes are usually under- or overestimated by up to $2.8 \mathrm{~cm}^{2}$.

Our study has some limitations. The retrospective design and the small number of patients remain the main limitations of our study. SDCT has been used in our department since April 2019. Therefore, only data within a timeframe of a little more than one year could be used. In addition, the detection of prevertebral hematomas on $\mathrm{C}+\mathrm{ED}$ reconstructions requires some practice and additional training is required for radiologists with little experience in interpreting $\mathrm{C}+\mathrm{ED}$ images in order to avoid misdiagnoses.

\section{Conclusion}

Our study shows that SDCT has improved diagnostic accuracy for detecting post-traumatic prevertebral hematomas of the cervical spine by using combined conventional and electron density images compared to conventional images alone. Therefore, combined conventional and electron density reconstructions on SDCT can be used for the pre-evaluation of prevertebral hematomas in an emergency setting. Nevertheless, prevertebral hematomas with a thickness of $3 \mathrm{~mm}$ or less cannot be reliably identified by SDCT. In contrast, there is no discernible value of conventional SDCT images with respect to diagnosing prevertebral hematomas.

\section{Conflict of Interest}

The authors declare that they have no conflict of interest.

\section{References}

[1] Ballane G, Cauley JA, Luckey MM et al. Worldwide prevalence and incidence of osteoporotic vertebral fractures. Osteoporosis International 2017; 28: 1531-1542

[2] Cosman F, Krege JH, Looker AC et al. Spine fracture prevalence in a nationally representative sample of US women and men aged $\geq 40$ years: results from the National Health and Nutrition Examination Survey (NHANES) 2013-2014. Osteoporosis International 2017; 28: 1857-1866

[3] Neuhaus V, Lennartz S, Abdullayev $\mathrm{N}$ et al. Bone marrow edema in traumatic vertebral compression fractures: diagnostic accuracy of dual-layer detector CT using calcium suppressed images. European journal of radiology 2018; 105: 216-220

[4] Kumar Y, Hayashi D. Role of magnetic resonance imaging in acute spinal trauma: a pictorial review. BMC musculoskeletal disorders 2016; 17: 310

[5] El-Khoury GY, Kathol MH, Daniel WW. Imaging of acute injuries of the cervical spine: value of plain radiography, CT, and MR imaging. Am J Roentgenol. American journal of roentgenology 1995; 164: 43-50

[6] Saifuddin A. MRI of acute spinal trauma. Skeletal radiology 2001; 30: 237246

[7] Penning L. Prevertebral hematoma in cervical spine injury: incidence and etiologic significance. Am J Roentgenol. American journal of roentgenology 1981; 136: 553-561

[8] Anagnostara A, Athanassopoulou A, Kailidou E et al. Traumatic retropharyngeal hematoma and prevertebral edema induced by whiplash injury. Emergency radiology 2005; 11: 145-149
[9] Chin KW, Sercarz JA, Wang MB et al. Spontaneous cervical hemorrhage with near-complete airway obstruction. Head \& Neck: Journal for the Sciences and Specialties of the Head and Neck 1998; 20: 350-353

[10] Senthuran S, Lim S, Gunning KE. Life-threatening airway obstruction caused by a retropharyngeal haematoma. Anaesthesia 1999; 54: 674678

[11] Duvillard C, Ballester M, Romanet P. Traumatic retropharyngeal hematoma: a rare and critical pathology needed for early diagnosis. European Archives of Oto-Rhino-Laryngology and Head \& Neck 2005; 262: 713715

[12] Ehn S, Sellerer T, Muenzel D et al. Assessment of quantification accuracy and image quality of a full-body dual-layer spectral CT system. Journal of applied clinical medical physics 2018; 19: 204-217

[13] Schwaiger B], Gersing AS, Hammel J et al. Three-material decomposition with dual-layer spectral CT compared to MRI for the detection of bone marrow edema in patients with acute vertebral fractures. Skeletal radiology 2018; 47: 1533-1540

[14] Rassouli N, Etesami M, Dhanantwari A et al. Detector-based spectral CT with a novel dual-layer technology: principles and applications. Insights into imaging 2017; 8: 589-598

[15] Muñoz A, Fischbein N], de Vergas ] et al. Spontaneous retropharyngeal hematoma: diagnosis by MR imaging. American journal of neuroradiology 2001; 22: 1209-1211

[16] Sobti S, Grewal SS, John PS et al. Massive Retropharyngeal Hematoma with Airway Obstruction after Minor Injury. Indian Journal of Neurotrauma 2017; 14: 95-97

[17] Tsai KJ, Huang YC. Traumatic retropharyngeal hematoma: case report. Journal of Trauma and Acute Care Surgery 1999; 46: 715-716

[18] Rojas CA, Vermess D, Bertozzi JC et al. Normal thickness and appearance of the prevertebral soft tissues on multidetector CT. American journal of neuroradiology 2009; 30: 136-141

[19] Henninger B, Kaser V, Ostermann S et al. Cervical disc and ligamentous injury in hyperextension trauma: MRI and intraoperative correlation. Journal of Neuroimaging 2020; 30: 104-109

[20] Utz M, Khan S, O'Connor D et al. MDCT and MRI evaluation of cervical spine trauma. Insights into imaging 2014; 5: 67

[21] Kawakyu-O'Connor D, Bordia R, Nicola R. Magnetic resonance imaging of spinal emergencies. Magnetic Resonance Imaging Clinics 2016; 24: 325-344

[22] Horwood L, Attili A, Luba F et al. Magnetic resonance imaging in patients with cardiac implanted electronic devices: focus on contraindications to magnetic resonance imaging protocols. EP Europace 2017; 19: 812-817

[23] Shefer E, Altman A, Behling R et al. State of the art of CT detectors and sources: a literature review. Current Radiology Reports 2013; 1: 76-91

[24] Abdullayev N, Hokamp NG, Lennartz S et al. Improvements of diagnostic accuracy and visualization of vertebral metastasis using multi-level virtual non-calcium reconstructions from dual-layer spectral detector computed tomography. European radiology 2019; 29: 5941-5949

[25] Zhang X, Liu M, Wang Y et al. Evaluating the temporomandibular joint disc using calcium-suppressed technique in dual-layer detector computed tomography. Journal of International Medical Research 2019. doi:10.1177/0300060519891332

[26] Mason JH, Perelli A, Nailon WH et al. Quantitative electron density CT imaging for radiotherapy planning Medical Image Understanding and Analysis. New York: Springer. 2017

[27] Ayyalusamy A, Vellaiyan S, Shanmugam S et al. Feasibility of offline head \& neck adaptive radiotherapy using deformed planning CT electron density mapping on weekly cone beam computed tomography. The British journal of radiology 2017; 90: doi:10.1259/bjr.20160420

[28] Vermess D, Rojas CA, Shaheen F et al. Normal pediatric prevertebral soft-tissue thickness on MDCT. Am J Roentgenol. American journal of roentgenology 2012; 199: W130-W133 